\title{
REAVI
}

\section{CARACTERÍSTICAS DA INFORMAÇÃO AMBIENTAL DAS EMPRESAS DA CONSTRUÇÃO CIVIL LISTADAS NA B3}

\section{CHARACTERISTICS OF THE ENVIRONMENTAL INFORMATION OF CIVIL CONSTRUCTION COMPANIES LISTED IN B3}

\author{
Izabelle Cris Dias de Brito* \\ Lívia Maria da Silva Santos**
}

\section{RESUMO}

O presente estudo tem o propósito de analisar as características da informação ambiental divulgadas pelas empresas da construção civil listadas na Brasil, Bolsa, Balcão. Para a realização da pesquisa, foram analisadas as Demonstrações Financeiras Padronizadas (DFPs), os Formulários de Referência (FR), os Relatórios Anuais (RAN) e de Sustentabilidade (RS), no período de 2010 a 2016. Para analisar as características da informação ambiental foi utilizada uma estrutura dividida em nove categorias, composta por 38 itens, de acordo com o estudo de Santos (2016). A partir da análise de conteúdo, foram definidos três critérios de classificação, que compreendem a evidência (declarativa, quantitativa monetária ou quantitativa e monetária), o tipo de notícia evidenciada (boa, ruim, ou neutra) e a localização da informação (DFPs, FR, RA e RS). Os resultados obtidos na pesquisa demonstram que as empresas concentram as informações ambientais, principalmente, nos Formulários de Referência. No que se refere ao tipo de notícia, foi possível perceber que cerca de $50 \%$ das empresas optam por divulgar notícias boas. As informações ruins compreenderam seis das dezoito empresas do estudo. Constatou-se que a maioria das informações foi divulgada pelas companhias de forma declarativa. Estes resultados contribuem para o entendimento de que, conforme enunciam as Teorias da Legitimidade e dos Stakeholders, as empresas, como forma de mostrar suas ações, de modo a atender a demanda informacional das suas partes interessadas e garantir a sua legitimidade, evidenciam informações de natureza ambiental, mesmo que não sejam obrigadas por força de lei. Palavras-chave: Evidenciação ambiental. Características da informação ambiental. Construção civil.

\begin{abstract}
This study aims to analyze the characteristics of environmental information disclosed by the construction companies listed in B3. In order to carry out the research, Standardized Financial Statements (DFPs), Reference Forms (FR), Annual Reports (RAN) and Sustainability Reports (RS) were analyzed, from 2010 to 2016. To analyze the characteristics of the information environment, a structure divided into nine categories was used, consisting of 38 items, according to the study by Santos (2016). From the content analysis, three classification criteria were defined, which comprise the evidence (declarative, monetary quantitative or quantitative and monetary), the type of news evidenced (good, bad, or neutral) and the location of the information (DFPs, FR, RA and RS). The results obtained in the research show that companies concentrate environmental information, mainly in Reference Forms. With regard to the type of news, it was

\footnotetext{
* UNIPÊ - CENTRO UNIVERSITÁRIO DE JOÃO PESSOA. E-mail: izabellecdb@hotmail.com

*** UNIR - FUNDAÇÃO UNIVERSIDADE FEDERAL DE RONDÔNIA. E-mail: livia.marias@ hotmail.com
} 
possible to notice that about $50 \%$ of companies choose to publish good news. The bad information comprised 6 of the 18 companies in the study. It was found that most information was disclosed by companies in a declarative manner. These results contribute to the understanding that, as enunciated by the Theories of Legitimacy and Stakeholders, companies, as a way to show their actions, in order to meet the informational demand of their interested parties, and guarantee their legitimacy, evidence information of an environmental nature, even if they are not required by law.

Keywords: Environmental Disclosure. Characteristics of Environmental Information. Construction.

Data de submissão: 26 de março de 2020.

Data de aprovação: 15 de junho de 2020.

Disponibilidade: http://www.revistas.udesc.br/index.php/reavi/index

\section{INTRODUÇÃO}

Ao longo do tempo, as tendências quanto à preocupação ambiental nas empresas vêm aumentando de forma substancial. De acordo com Dias (2017), nos últimos anos, se tornou uma estratégia organizacional considerar, no planejamento empresarial, a gestão ambiental, motivada pelo aumento do acesso à informação da maior parte da população e pela maneira como será vista por seus stakeholders.

As empresas que incorporam ações de responsabilidade ambiental perante a sociedade buscam corresponder aos interesses, não apenas dos sócios e proprietários, mas de todas as partes. As empresas precisam, além de demonstrar os aspectos econômicos das suas atividades, evidenciar a sua preocupação com o meio ambiente e as questões sociais. Demonstrando essas informações, tornam-se mais competitivas, atraem consumidores e investidores e harmonizam os seus interesses com os da comunidade (LIMA et al., 2012).

Para alcançar o desempenho desejado, é importante que as organizações busquem divulgar informações de cunho ambiental. De acordo com Murcia et al. (2010), nas diversidades de informações relativas às operações da empresa, estão as informações ambientais. Ainda segundo os autores, a evidenciação dessas informações é considerada relevante, tendo em vista que eventos ambientais, a exemplo de multas e passivos ambientais, podem impactar a saúde financeira de uma entidade.

O segmento da Construção civil é considerado importante para o desenvolvimento econômico e social do Brasil. Teixeira e Carvalho (2005) definem o setor da construção civil como um setor econômico importante pelo impacto direto na economia brasileira e na geração de emprego, renda e tributos, apontam como um setor-chave para o desenvolvimento do país. Por outro lado, é o setor que provoca grandes impactos ambientais. Vilhena (2007) afirma que os empreendimentos da construção civil são um dos maiores agressores ao meio ambiente. As atividades relacionadas à construção promovem a degradação ambiental, por meio do execesso de consumo dos recursos naturais e da produção de resíduos. Tais fatos estimulam o desenvolvimento da presente pesquisa neste setor importante para a economia brasileira. 


\section{REAVI}

Sob essas perspectivas, avaliando a integração das questões ambientais ao planejamento estratégico empresarial, surge a seguinte indagação, que norteia a pesquisa: Quais são as características da informação ambiental das empresas da construção civil listadas na B3?

Diante da eminência do tema e na tentativa de responder ao problema da pesquisa, o presente estudo tem como objetivo geral analisar as características da informação ambiental divulgadas pelas empresas da construção civil listadas na B3.

Este estudo se justifica pela relevância crescente da demanda da sociedade por maior accountability, pela geração de conhecimento acerca do assunto, e, socioambientalmente, pela geração de impactos ambientais do setor da construção civil e a busca associada à compreensão das características da informação ambiental (ROVER; BORBA; MURCIA, 2009; VECHI; GALLARDO; TEIXEIRA, 2016).

Segundo Maia (2010), o conhecimento sobre os conceitos e características da informação ambiental é importante para a compreensão e utilização da sociedade, em geral, que se interessa pela pesquisa e, também, para conscientização e preservação do meio ambiente. Trabalhos com temática semelhante foram desenvolvidos, ao longo dos anos, inclusive envolvendo o ramo da construção civil (ROVER, 2009; CUNHA; BEUREN; CARDOZO, 2010; MENDES; MOREIRA; RODRIGUES, 2012); no entanto, esta pesquisa abarca um período de estudo diferente, mais recente, possibilitando, assim, uma análise mais atual acerca das características das informações ambientais que as empresas da construção civil evidenciam.

Acredita-se que a presente pesquisa irá contribuir na disseminação de conhecimento relacionado ao tipo de informação que as empresas da construção divulgam em seus relatórios, ou seja, se estão sendo transparentes e retratando, de fato, a realidade das atividades organizacionais, incluindo os impactos que, porventura, tenham provocado no meio ambiente, considerando a conscientização da sociedade e de grupos específicos, quanto às questões ambientais, nos últimos anos, que têm exigido uma postura socioambiental responsável por parte das empresas, assim como sua divulgação (SANTOS, 2016).

\section{FUNDAMENTAÇÃO TEÓRICA}

\subsection{TEORIA DOS STAKEHOLDERS E DA LEGITIMIDADE}

O termo Stakeholder, segundo Ladeira (2009), surgiu, em 1963, referindo-se a um grupo, cujo suporte era essencial para que a organização funcionasse e existisse. O termo, em português, significa "parte interessada" ou "interveniente", referindo-se a todos os envolvidos nos processos da organização, ou seja, àqueles que podem afetar ou são afetados no alcance dos objetivos de uma entidade, a exemplo dos clientes, colaboradores, investidores, fornecedores e comunidade. De acordo com Rover (2009), a Teoria dos Stakeholders afirma que, para continuar operando durante um longo tempo, as organizações dependem da aprovação e suporte dos stakeholders. Ulman (1985) argumenta que isso acontece por causa da sua capacidade de controlar os recursos necessários para as operações da organização.

Os investidores, por exemplo, têm um cuidado para que seus nomes não estejam ligados a organizações que não demonstrem preocupações com as questões ambientais (LADEIRA, 2008). Considerando, pois, que as atividades da empresa precisam ser aceitas pelas partes interessadas, a divulgação de informação de natureza ambiental é utilizada como um meio de comunicação entre elas. Deegan (2002) afirma que os gestores possuem incentivos para divulgar informações 
sobre os diversos programas e iniciativas da empresa, tendo em vista que, a partir disso, indicam que estão em conformidade com as expectativas das suas partes interessadas.

Assim como a teoria dos stakeholders, a Teoria da Legitimidade reconhece a relação da entidade e a sociedade na qual está inserida. Esta relação é baseada na existência de um "contrato social", com expectativas explícitas ou implícitas, atuando sob as limitações impostas pela sociedade (DEEGAN, 2002).

Conforme menciona Patten (1992), as organizações são consideradas legítimas quando evidenciam, de forma voluntária, as informações sociais e ambientais. Segundo Czesnat e Machado (2012, p. 294), "uma empresa é legitimada pela sociedade à medida que seus valores e crenças se alinham aos valores e crenças que a sociedade entende como corretos". Na área contábil, a Teoria da Legitimidade pode ser compreendida como a relação das informações prestadas pelas organizações às partes interessadas. Em forma de exigências dos consumidores, por meio de leis e regulamentos, ou cobrança de fornecedores, as empresas são pressionadas a evidenciar tais informações (FARIAS, 2008).

A divulgação ambiental pode ser considerada como uma ferramenta de legitimação da atividade empresarial. Os relatórios anuais e ambientais têm sido o principal recurso para a comunicação das empresas com os seus stakeholders na evidenciação ambiental de informações (EUGÊNIO, 2010). De acordo com Lu e Abeysekera (2014), a Teoria dos Stakeholders e da Legitimidade devem ser trabalhadas em conjunto, por fornecer melhores explicações sobre as práticas de divulgação ambiental das empresas, uma vez que a primeira está relacionada às expectativas da sociedade em geral, enquanto a segunda, de determinados grupos de interesse.

\subsection{EVIDENCIAÇÃO AMBIENTAL}

A evidenciação ambiental é considerada uma ferramenta de comunicação utilizada pelas empresas para responder a demanda de informações das partes interessadas, a saber, governo, fornecedores, clientes, acionistas, credores, administradores, funcionários, associações, dentre outros (SILVA et al., 2013), demonstrando, com isso, o cumprimento da sua responsabilidade social corporativa (LU; ABEYSEKERA, 2014). A divulgação dessas informações, geralmente, é feita por meio de relatórios, seja nas Demonstrações Financeiras Padronizadas, Relatórios de Sustentabilidade e/ou Anuais, Formulários de Referência e Balanço Social.

Conforme mencionam Rosa et al. (2012), a evidenciação ambiental pode ser definida como o meio ou um conjunto de meios utilizados pelas organizações para evidenciar suas práticas em relação ao meio ambiente, ou seja, sobre o resultado da sua gestão ambiental, aumentando, assim, a transparência organizacional (PLETSCH et al., 2014). A divulgação de informações de cunho ambiental, no Brasil, não é obrigatória. Neste sentido, do ponto de vista legal, ainda são tímidas as diretrizes para a divulgação de informações dessa natureza nas demonstrações financeiras. O que se tem, na verdade, são algumas orientações e recomendações emitidas pelos órgãos que influenciam a atividade contábil e a elaboração das demonstrações, a saber, Comissão de Valores Mobiliários (CVM), Instituto dos Auditores Independentes do Brasil (IBRACON) e Conselho Federal de Contabilidade (CFC) (ROVER et al., 2012).

A CVM, por meio do Parecer de Orientação 15, de 1987, sugere que as empresas de capital aberto divulguem, em seus Relatórios da Administração, informações sobre a proteção do meio ambiente. O IBRACON, por sua vez, criou a Norma e Procedimento de Auditoria, em 1996, recomendando que os ativos e passivos ambientais sejam divulgados em títulos 
específicos, nas demonstrações contábeis das empresas. Já o Conselho Federal de Contabilidade (CFC) aprovou a Norma Brasileira de Contabilidade Técnica 15 (NBC T15), que institui a Demonstração de Informação de Natureza Social e Ambiental (CARNEIRO; DE LUCA; OLIVEIRA, 2008; PIRES; SILVEIRA, 2008; SANTOS et al., 2019).

A evidenciação de informações voluntárias é um importante mecanismo para reduzir a assimetria de informação entre os agentes. Além disso, tal divulgação tem sido utilizada pelas empresas, com o propósito de elevar o seu valor de mercado e sua credibilidade frente aos stakeholders, favorecendo, como consequência, a obtenção de financiamentos, novos mercados e retornos financeiros (FERNANDES, 2013). Pereira, Luz e Carvalho (2015) corroboram o exposto, ao pontuarem que a questão ambiental pode tornar-se uma estratégia empresarial, que pode possibilitar benefícios ambientais, econômicos e sociais para todos os stakeholders.

Sendo assim, as organizações devem evidenciar, de forma transparente, as informações ambientais (NOSSA, 2002), não ficando limitadas a divulgar apenas as informações impostas por lei, a fim de que suas partes interessadas possam ter conhecimento amplo e verdadeiro das suas atividades.

\section{METODOLOGIA}

O presente estudo busca analisar as características da informação ambiental divulgadas pelas empresas da construção civil listadas na B3. Dessa forma, pelo da pesquisa ter o objetivo de identificar as principais características de determinado objeto de estudo, que, neste caso, são as informações ambientais, classifica-se como descritiva.

A amostra pesquisada constitui um universo de 18 empresas de capital aberto, com ações negociadas na Brasil, Bolsa, Balcão, mais conhecida como B3, do segmento da construção civil, conforme evidenciado no Quadro 1.

Quadro 1 - Amostra da Pesquisa

\begin{tabular}{|l|}
\hline \multicolumn{1}{|c|}{ Empresas da Construção Civil Listadas na B3 } \\
\hline Construtora Adolpho Lindenberg S.A. \\
\hline Construtora Tenda S.A. \\
\hline CR2 Empreendimentos Imobiliarios S.A. \\
\hline Cyrela Brazil Realty S.A.Empreendimentos e Participações \\
\hline Direcional Engenharia S.A. \\
\hline Even Construtora e Incorporadora S.A. \\
\hline EZ TEC Empreendimentos e Participações S.A. \\
\hline Gafisa S.A. \\
\hline Helbor Empreendimentos S.A. \\
\hline JHSF Participacoes S.A. \\
\hline João Fortes Engenharia S.A. \\
\hline MRV Engenharia e Participações S.A. \\
\hline PDG Realty S.A. Empreendimentos e Participações \\
\hline RNI Negócios Imobiliários S.A. \\
\hline Rossi Residencial S.A. \\
\hline Tecnisa S.A. \\
\hline Trisul S.A. \\
\hline Viver Incorporadora e Construtora S.A. \\
\hline
\end{tabular}

Fonte: Dados da Pesquisa (2017). 
Quanto aos procedimentos técnicos, trata-se de uma pesquisa documental. O caráter documental se concretiza por meio da análise das Demonstrações Financeiras Padronizadas (DFPs), Relatórios de Sustentabilidade (RS) e Relatórios Anuais, Relatórios de Administração e Formulários de Referência das empresas da Construção Civil. Além disso, quanto à abordagem do problema, trata-se de uma pesquisa qualitativa, considerando a finalidade de se conhecer as características das informações ambientais.

Para a realização da pesquisa, os dados foram extraídos das Demonstrações Financeiras Padronizadas (DFPs), dos Formulários de Referência (FR) e dos Relatórios Anuais (RAN) e de Sustentabilidade (RS) das empresas, no período de 2010 a 2016. Este período se justifica pelo fato dos Formulários de Referência só estarem disponíveis, no site da B3, a partir de 2010, e pelo fato da coleta ter sido realizada em março de 2017. Esses formulários apresentam informações de diversas naturezas, inclusive informações ambientais, podendo, dessa forma, ser importantes para a análise do estudo. Para análise das informações ambientais, foi aplicada a técnica de análise de conteúdo.

Com a finalidade de analisar as características da informação ambiental foi utilizado uma estrutura dividida em nove categorias, composta por 38 itens, de acordo com o estudo de Santos (2016), conforme apresentado no Quadro 2.

Quadro 2 Categorias para análise da evidenciação de informações ambientais

\begin{tabular}{|c|c|c|}
\hline Categoria & Item & Subcategoria \\
\hline \multirow{5}{*}{ 1. Políticas Ambientais } & 1 & Declaração das políticas, práticas e ações atuais e futuras \\
\hline & 2 & Estabelecimento de metas e objetivos ambientais \\
\hline & 3 & $\begin{array}{l}\text { Declaração indicando que a empresa está (ou não) em obediência (compliance) } \\
\text { com as leis, licenças, normas e órgãos ambientais }\end{array}$ \\
\hline & 4 & Parcerias ambientais \\
\hline & 5 & Prêmios e participações em índices ambientais \\
\hline \multirow{3}{*}{ 2. Gestão Ambiental } & 6 & Gestão Ambiental \\
\hline & 7 & Certificações de qualidade \\
\hline & 8 & Auditoria Ambiental \\
\hline \multirow{2}{*}{$\begin{array}{l}\text { 3. Impactos dos } \\
\text { Produtos e Processos } \\
\text { no Meio Ambiente }\end{array}$} & 9 & Desperdícios de resíduos \\
\hline & 10 & Impacto no meio ambiente (vazamentos, derramamentos, terra utilizada, etc.) \\
\hline \multirow{7}{*}{$\begin{array}{l}\text { 4. Mitigação, } \\
\text { reparação e } \\
\text { compensação de danos } \\
\text { ao Meio Ambiente }\end{array}$} & 11 & Reciclagem e resíduo \\
\hline & 12 & Desenvolvimento de produtos ecológicos \\
\hline & 13 & Uso eficiente e reutilização da água \\
\hline & 14 & Reparos aos danos ambientais \\
\hline & 15 & Menção a investimentos ambientais \\
\hline & 16 & Medidas de segurança ambiental \\
\hline & 17 & Indicadores ambientais \\
\hline \multirow{3}{*}{ 5. Energia } & 18 & Conservação e/ou utilização mais eficiente nas operações \\
\hline & 19 & Utilização de materiais desperdiçados na produção de energia \\
\hline & 20 & Desenvolvimento ou exploração de novas fontes de energia \\
\hline \multirow{5}{*}{$\begin{array}{l}\text { 6. Informações } \\
\text { Financeiras } \\
\text { Ambientais }\end{array}$} & 21 & Valor dos investimentos ambientais \\
\hline & 22 & Montante dos custos e/ou despesas ambientais \\
\hline & 23 & Passivos ambientais \\
\hline & 24 & Práticas contábeis de itens ambientais \\
\hline & 25 & Seguro Ambiental \\
\hline
\end{tabular}

Continua... 
...continuação.

\begin{tabular}{|l|c|l|}
\hline \multicolumn{1}{|l}{26} & Ativos ambientais intangíveis \\
\hline 7. Educação e \\
Pesquisa Ambiental & 27 & Educação Ambiental (internamente e/ou comunidade) \\
\cline { 2 - 3 } $\begin{array}{l}\text { 8. Mercado de } \\
\text { Créditos de Carbono }\end{array}$ & 28 & Pesquisa relacionadas ao meio ambiente \\
\cline { 2 - 3 } & 29 & Projetos de Mecanismos de Desenvolvimento Limpo \\
\cline { 2 - 3 } & 31 & Crédito de Carbono \\
\cline { 2 - 3 } & 32 & Emissão de Gases Efeito Estufa (GEE) \\
\hline \multirow{4}{*}{$\begin{array}{l}\text { 9. Outras Informações } \\
\text { Ambientais }\end{array}$} & 33 & Expectados de emissões reduzidas (CER) \\
\cline { 2 - 3 } & 34 & Gerenciamento de florestas e/ou reflorestamento \\
\cline { 2 - 3 } & 35 & Conservação da Biodiversidade \\
\cline { 2 - 3 } & 36 & Paisagismo e jardinagem (landscaping) \\
\cline { 2 - 3 } & 37 & Relacionamento Ambiental com stakeholders \\
\cline { 2 - 3 } & 38 & $\begin{array}{l}\text { Número de queixas e reclamações relacionadas a impactos ambientais registradas, } \\
\text { processadas e solucionadas por meio de mecanismo formal }\end{array}$ \\
\hline
\end{tabular}

Fonte: Adaptado de Santos (2016).

Para cada item divulgado nos Relatórios das empresas, foi atribuído o valor 1 (um), caso contrário, o valor 0 (zero). A partir da análise de conteúdo foram definidos três critérios de classificação, com base no trabalho de Rover (2009), conforme ilustrado na Figura 1.

Figura 1: Esquema para classificação do disclosure ambiental

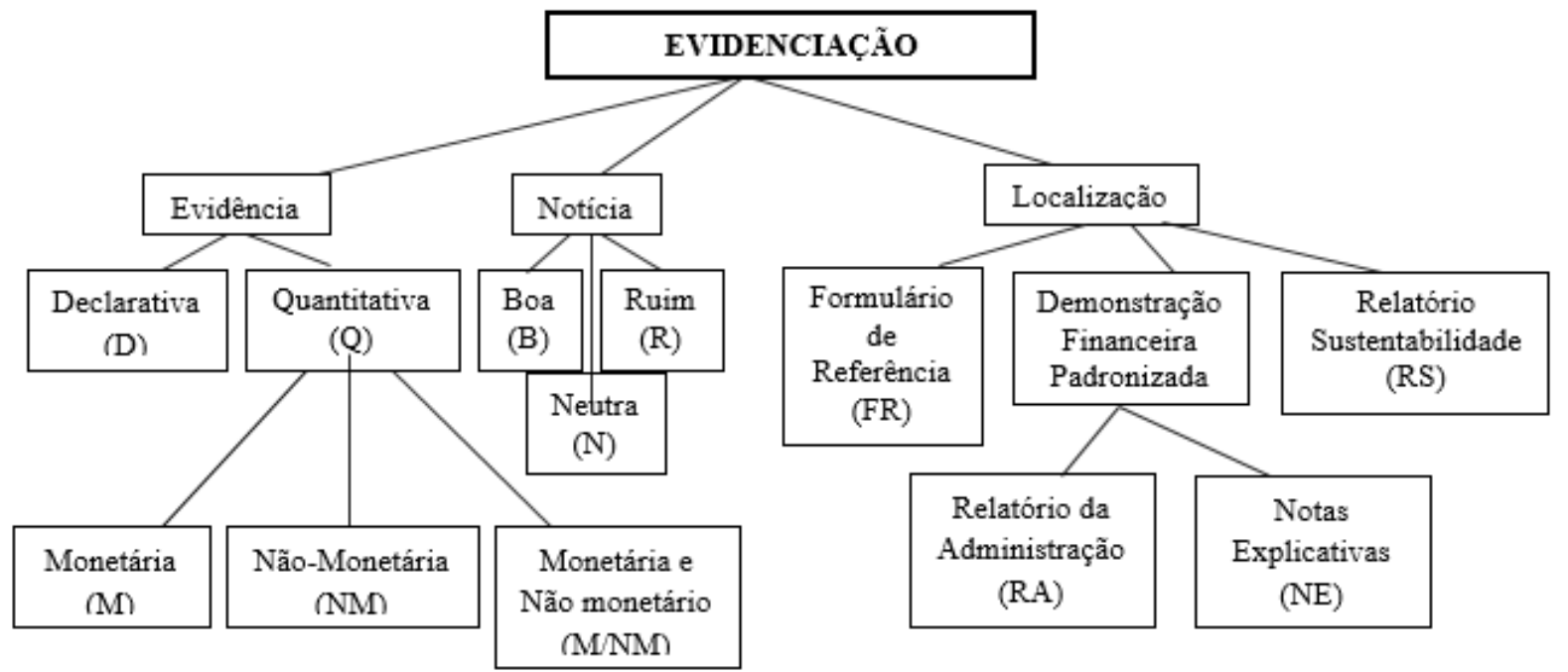

Fonte: Adaptado de Rover (2009).

Conforme Figura 1, classificou-se a informação obtida da seguinte forma:

- Declarativa: Informação qualitativa expressa em termos descritos;

- Quantitativa Monetária: informação quantitativa expressa em números;

- Quantitativa Monetária e Não monetária: informação quantitativa expressa em números de natureza financeira e não financeira.

Para a análise do tipo de notícia, foram destacadas três categorias:

- Informação Boa: declarações que reflitam crédito para a companhia;

- Informação Ruim: declarações que reflitam descrédito para a companhia;

Revista Eletrônica do Alto Vale do Itajaí - REAVI, v.09, nº 14, p. 040-054, ago. 2020.

ISSN: 2316-4190, DOI 10.5965/2316419009142020040 
- Informação Neutra: declarações cujo crédito/descrédito para a empresa não é claro.

Quanto à localização, buscou-se investigar onde a informação foi divulgada classificando-as em quatro grupos:

\section{- Demonstrações Financeiras Padronizadas;}

- $\quad$ Formulários de Referência;

- $\quad$ Relatório de Sustentabilidade.

\section{ANÁLISE DOS RESULTADOS}

Neste tópico, serão apresentadas as análises das 9 categorias ambientais e os resultados das características da informação ambiental. Na sequência, apresentam-se, por meio da Tabela 1, os resultados da análise de evidenciação das categorias ambientais das empresas do setor da construção civil analisadas.

Tabela 1 - Evidenciação das categorias Ambientais

\begin{tabular}{l|c|c|c|c|c|c|c|c}
\multicolumn{1}{c|}{ Categorias } & $\mathbf{2 0 1 0}$ & $\mathbf{2 0 1 1}$ & $\mathbf{2 0 1 2}$ & $\mathbf{2 0 1 3}$ & $\mathbf{2 0 1 4}$ & $\mathbf{2 0 1 5}$ & $\mathbf{2 0 1 6}$ & $\begin{array}{c}\mathbf{N}^{\mathbf{M}} \text { Médio de } \\
\text { divulgações }\end{array}$ \\
\hline Políticas Ambientais & 15 & 16 & 17 & 17 & 17 & 16 & 17 & $\mathbf{1 6 , 4 2}$ \\
\hline Gestão Ambiental & 14 & 14 & 14 & 14 & 14 & 13 & 13 & $\mathbf{1 3 , 7 1}$ \\
\hline $\begin{array}{l}\text { Impactos dos Produtos e Processos no } \\
\text { Meio Ambiente }\end{array}$ & 4 & 4 & 3 & 3 & 3 & 3 & 3 & $\mathbf{3 , 2 8}$ \\
\hline $\begin{array}{l}\text { Mitigação, reparação e compensação de } \\
\text { danos ao Meio Ambiente }\end{array}$ & 12 & 11 & 12 & 13 & 12 & 11 & 10 & $\mathbf{1 1 , 5 7}$ \\
\hline Energia & 5 & 5 & 5 & 7 & 7 & 5 & 6 & $\mathbf{5 , 7 1}$ \\
\hline Informações Financeiras Ambientais & 4 & 5 & 5 & 5 & 5 & 4 & 5 & $\mathbf{4 , 7 1}$ \\
\hline Educação e Pesquisa Ambiental & 6 & 6 & 6 & 8 & 7 & 7 & 7 & $\mathbf{6 , 7 1}$ \\
\hline Mercado de Créditos de Carbono & 4 & 4 & 4 & 5 & 5 & 3 & 3 & $\mathbf{4}$ \\
\hline Outras Informações Ambientais & 5 & 6 & 6 & 8 & 7 & 7 & 7 & $\mathbf{6 , 5 7}$ \\
\hline Fonf
\end{tabular}

Fonte: Dados da Pesquisa (2017).

Verifica-se, conforme a Tabela 1, que, das 9 categorias analisadas no estudo, aquela que apresentou maior média de divulgação foi a de 'Políticas Ambientais'; ou seja, em média, 16 empresas demonstram suas ações perante o meio ambiente. Este fato pode ser justificado em razão da existência da subcategoria 'Declarações das Políticas e Práticas Atuais e Futuras', que obteve maior participação de evidenciação pelas companhias.

Tal resultado foi consistente com as pesquisas de Murcia et al. (2008), Rover (2009) e Rover, Borba e Murcia (2009), embora tais estudos tenham, como amostra, as empresas potencialmente poluidoras, que não é o caso da presente pesquisa. Os estudos supracitados verificaram que essa categoria se destacou, com a maior evidenciação ambiental.

A categoria 'Impactos dos Produtos e Processos no Meio Ambiente', por outro lado, foi a categoria com menos destaque; teve representatividade de evidenciação de, aproximadamente, 3 empresas da amostra. Isso pode ser explicado, pelo fato desta categoria compreender, em sua maioria, informações ruins, a exemplo de desperdícios de resíduos, impactos no meio ambiente, como vazamentos, derramamentos, terra utilizada, etc., ou, até mesmo, informações neutras, conforme foi apresentado no estudo de Rover, Borba e Murcia (2009).

A companhia que obteve maior índice de itens divulgados foi a empresa Even, com cerca de $81,57 \%$. Tais resultados sugerem, dessa forma, que as empresas tendem a divulgar

Revista Eletrônica do Alto Vale do Itajaí - REAVI, v.09, nº 14, p. 040-054, ago. 2020.

ISSN: 2316-4190, DOI 10.5965/2316419009142020040 


\section{REAVI}

voluntariamente mais informações ambientais que sejam positivas do que as que são negativas para as organizações (DYE, 2001).

$\mathrm{Na}$ Tabela 2 estão evidenciados os dados relacionados à localização das informações ambientais.

Tabela 2 - Localização por empresa das categorias ambientais

\begin{tabular}{|c|c|c|c|c|c|c|c|c|c|c|c|c|c|c|c|c|c|c|c|c|c|}
\hline \multirow{2}{*}{ Categorias } & \multicolumn{3}{|c|}{2010} & \multicolumn{3}{|c|}{2011} & \multicolumn{3}{|c|}{2012} & \multicolumn{3}{|c|}{2013} & \multicolumn{3}{|c|}{2014} & \multicolumn{3}{|c|}{2015} & \multicolumn{3}{|c|}{2016} \\
\hline & FR & DF & $\mathrm{RS}$ & FR & DF & $\mathrm{RS}$ & FR & DF & $\mathrm{RS}$ & FR & DF & $\mathrm{RS}$ & FR & DF & RS & FR & DF & RS & FR & DF & RS \\
\hline Políticas Ambientais & 14 & 7 & 2 & 11 & 9 & 3 & 14 & 8 & 4 & 15 & 8 & 4 & 14 & 7 & 4 & 15 & 6 & 3 & 14 & 6 & 3 \\
\hline Gestão Ambiental & 10 & 3 & 3 & 12 & 3 & 3 & 14 & 3 & 4 & 13 & 2 & 4 & 12 & 3 & 4 & 13 & 0 & 3 & 13 & 0 & 3 \\
\hline $\begin{array}{l}\text { Impactos dos } \\
\text { Produtos e Processos } \\
\text { no Meio Ambiente }\end{array}$ & 2 & 0 & 3 & 3 & 0 & 3 & 3 & 0 & 2 & 2 & 0 & 3 & 2 & 0 & 3 & 2 & 0 & 2 & 1 & 0 & 3 \\
\hline $\begin{array}{l}\text { Mitigação, } \\
\text { Reparação e } \\
\text { Compensação de } \\
\text { danos ao Meio } \\
\text { Ambiente }\end{array}$ & 9 & 2 & 3 & 7 & 2 & 3 & 10 & 2 & 4 & 12 & 2 & 2 & 10 & 2 & 4 & 11 & 0 & 3 & 10 & 1 & 3 \\
\hline Energia & 1 & 1 & 3 & 2 & 2 & 3 & 2 & 2 & 3 & 1 & 2 & 4 & 2 & 2 & 3 & 1 & 0 & 3 & 1 & 0 & 3 \\
\hline $\begin{array}{l}\text { Informações } \\
\text { Financeiras } \\
\text { Ambientais }\end{array}$ & 5 & 2 & 0 & 5 & 2 & 0 & 5 & 2 & 1 & 4 & 1 & 2 & 4 & 1 & 2 & 4 & 1 & 2 & 4 & 1 & 1 \\
\hline $\begin{array}{l}\text { Educação e Pesquisa } \\
\text { Ambiental }\end{array}$ & 5 & 2 & 3 & 4 & 2 & 3 & 4 & 1 & 3 & 5 & 1 & 4 & 5 & 0 & 3 & 5 & 1 & 3 & 6 & 1 & 3 \\
\hline $\begin{array}{l}\text { Mercado de Créditos } \\
\text { de Carbono }\end{array}$ & 1 & 0 & 2 & 1 & 2 & 3 & 2 & 2 & 2 & 3 & 2 & 4 & 3 & 1 & 3 & 2 & 1 & 3 & 2 & 1 & 3 \\
\hline $\begin{array}{l}\text { Outras Informações } \\
\text { Ambientais }\end{array}$ & 4 & 3 & 2 & 3 & 4 & 3 & 5 & 2 & 4 & 7 & 2 & 4 & 6 & 1 & 4 & 7 & 1 & 3 & 7 & 1 & 3 \\
\hline $\begin{array}{l}\text { Legenda da Localizac } \\
\text { FR - Formulário de } \mathrm{F} \\
\text { DF - Demonstrações } \\
\text { RS - Relatórios Anua }\end{array}$ & ha & 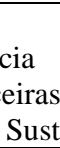 & atab & ilida & des & & & & & & & & & & & & & & & & \\
\hline
\end{tabular}

Fonte: Dados da Pesquisa, 2017.

Por meio dos dados evidenciados na Tabela 2, percebe-se que a maioria das empresas concentra as informações ambientais nos Formulários de Referência, atingindo 83\% da amostra. A participação é justificável pela exigibilidade da divulgação das atividades do emissor no referido formulário. Em relação às DFPs, as informações ambientais são evidenciadas, principalmente, nos Relatórios de Administração, assim como encontrado no trabalho de Murcia et al. (2008), que mostrou que 479 sentenças de informações estão localizadas no Relatório da Administração, 128 em Notas Explicativas e nenhuma no corpo das Demonstrações Contábeis.

Quanto aos Relatórios Anuais e de Sustentabilidade, as informações ambientais foram divulgadas por cerca de $20 \%$ das empresas da amostra. Tal resultado é decorrente da não adoção desses relatórios pelas companhias, onde 14 empresas não possuem este meio de comunicação. Por outro lado, confrontando os resultados obtidos, Rover (2009), em seu estudo com as empresas brasileiras potencialmente poluidoras, demonstrou que, de 2005 a 2007, as 57 empresas, que constituíram a amostra do estudo, evidenciaram $73 \%$ das informações ambientais nos Relatórios de Sustentabilidade e 27\% nas DFPs.

Estes resultados revelam que o fato de algumas empresas não possuir Relatório de Sustentabilidade não implica dizer que elas não evidenciam informações de caráter ambiental, considerando que há outros relatórios que elas utilizam como canal de comunicação. Pires e 
Silveira (2008) expõem que o objetivo é divulgar, para os stakeholders, informações relativas ao desempenho ambiental das entidades, assim como as que afetam o meio ambiente e o seu patrimônio. Para tanto, tal evidenciação pode ser realizada em relatórios específicos ou nas próprias demonstrações contábeis (COSTA; MARION, 2007).

A Tabela 3 apresenta a quantidade de empresas que evidenciou informações ambientais, que são classificadas quanto ao tipo de notícia publicada.

Tabela 3 - Tipo de notícia das categorias ambientais

\begin{tabular}{|c|c|c|c|c|c|c|c|c|c|c|c|c|c|c|c|c|c|c|c|c|c|}
\hline \multirow{2}{*}{ Categorias } & \multicolumn{3}{|c|}{2010} & \multicolumn{3}{|c|}{2011} & \multicolumn{3}{|c|}{2012} & \multicolumn{3}{|c|}{2013} & \multicolumn{3}{|c|}{2014} & \multicolumn{3}{|c|}{2015} & \multicolumn{3}{|c|}{2016} \\
\hline & $\mathrm{B}$ & $\mathrm{R}$ & $\mathrm{N}$ & $\mathrm{B}$ & $\mathrm{R}$ & $\mathrm{N}$ & $\mathrm{B}$ & $\mathrm{R}$ & $\mathrm{N}$ & $\mathrm{B}$ & $\mathrm{R}$ & $\mathrm{N}$ & $\mathrm{B}$ & $\mathrm{R}$ & $\mathrm{N}$ & $\mathrm{B}$ & $\mathrm{R}$ & $\mathrm{N}$ & $\mathrm{B}$ & $\mathrm{R}$ & $\mathrm{N}$ \\
\hline Políticas Ambientais & 9 & 6 & 0 & 10 & 6 & 0 & 11 & 6 & 0 & 11 & 6 & 0 & 11 & 6 & 0 & 10 & 6 & 0 & 11 & 6 & 0 \\
\hline Gestão Ambiental & 14 & 0 & 0 & 14 & 0 & 0 & 14 & 0 & 0 & 14 & 0 & 0 & 14 & 0 & 0 & 13 & 0 & 0 & 13 & 0 & 0 \\
\hline $\begin{array}{l}\text { Impactos ao Meio } \\
\text { Ambiente }\end{array}$ & 0 & 3 & 1 & 3 & 0 & 1 & 3 & 0 & 1 & 2 & 0 & 1 & 2 & 0 & 1 & 2 & 0 & 1 & 2 & 0 & 1 \\
\hline $\begin{array}{l}\text { Mitigação de danos } \\
\text { ao Meio Ambiente }\end{array}$ & 12 & 0 & 0 & 11 & 0 & 0 & 12 & 0 & 0 & 13 & 0 & 0 & 12 & 0 & 0 & 11 & 0 & 0 & 10 & 0 & 0 \\
\hline Energia & 5 & 0 & 0 & 5 & 0 & 0 & 5 & 0 & 0 & 7 & 0 & 0 & 7 & 0 & 0 & 5 & 0 & 0 & 6 & 0 & 0 \\
\hline $\begin{array}{l}\text { Informações } \\
\text { Financeiras } \\
\text { Ambientais } \\
\end{array}$ & 4 & 0 & 0 & 5 & 0 & 0 & 5 & 0 & 0 & 5 & 0 & 0 & 7 & 0 & 0 & 5 & 0 & 0 & 6 & 0 & 0 \\
\hline $\begin{array}{l}\text { Educação e Pesquisa } \\
\text { Ambiental }\end{array}$ & 6 & 0 & 0 & 6 & 0 & 0 & 6 & 0 & 0 & 8 & 0 & 0 & 7 & 0 & 0 & 7 & 0 & 0 & 7 & 0 & 0 \\
\hline $\begin{array}{l}\text { Mercado de Créditos } \\
\text { de Carbono }\end{array}$ & 4 & 0 & 0 & 4 & 0 & 0 & 4 & 0 & 0 & 5 & 0 & 0 & 5 & 0 & 0 & 3 & 0 & 0 & 3 & 0 & 0 \\
\hline $\begin{array}{l}\text { Outras Informações } \\
\text { Ambientais }\end{array}$ & 5 & 0 & 0 & 5 & 1 & 0 & 6 & 0 & 0 & 8 & 0 & 0 & 7 & 0 & 0 & 7 & 0 & 0 & 7 & 0 & 0 \\
\hline $\begin{array}{l}\text { Legenda do tipo de No } \\
\text { B - Boa; } \\
\text { R - Ruim; } \\
\text { N- Neutra. }\end{array}$ & & & & & & & & & & & & & & & & & & & & & \\
\hline
\end{tabular}

Fonte: Dados da Pesquisa, 2017

Quanto ao tipo de notícia, verificou-se que a maioria das companhias opta por divulgar notícias boas, que refletem crédito para empresa, tendo representatividade acima de $50 \%$. Estes resultados são similares aos desfechos dos estudos de Murcia et al. (2008), Rover (2009) e Rover, Borba e Murcia (2009), nas empresas potencialmente poluidoras, concluindo que a maior parte das informações divulgadas por estas são consideradas informações boas. Contudo, observa-se a incidência de informações ruins na categoria 'Políticas Ambientais', onde 6, das 18 empresas, demonstraram, em seus relatórios, que não estão em conformidade com a legislação ambiental. Dessa forma, a subcategoria 'Declaração, indicando que a empresa está (ou não) em obediência com as leis, licenças, normas e órgãos ambientais', possui sentido negativo e é concernente aos processos judiciais em que as organizações estão envolvidas.

A divulgação de informações negativas, por algumas empresas, acontece, segundo Rover et al. (2008), porque elas se veem obrigadas a evidenciar tais informações, para não incorrer no problema de seleção adversa; ou seja, as partes interessadas irão interpretar o fato da empresa não ter divulgado porque está omitindo informações desfavoráveis, ao contrário, das empresas com boas notícias, que possuem incentivos para divulgá-la (DYE, 1985). 


\section{REAVI}

Em seguida, verificou-se o tipo de evidência das categorias ambientais das informações evidenciadas pelas empresas, conforme Tabela 4.

Tabela 4 - Classificação da evidência das categorias ambientais

\begin{tabular}{|c|c|c|c|c|c|c|c|c|c|c|c|c|c|c|}
\hline \multirow{2}{*}{ Categorias } & \multicolumn{2}{|c|}{2010} & \multicolumn{2}{|c|}{2011} & \multicolumn{2}{|c|}{2012} & \multicolumn{2}{|c|}{2013} & \multicolumn{2}{|c|}{2014} & \multicolumn{2}{|c|}{2015} & \multicolumn{2}{|c|}{2016} \\
\hline & $\mathrm{D}$ & $\mathrm{Q}$ & D & $\mathrm{Q}$ & $\mathrm{D}$ & Q & $\mathrm{D}$ & Q & $\mathrm{D}$ & Q & $\mathrm{D}$ & Q & D & Q \\
\hline Políticas Ambientais & 9 & 6 & 10 & 6 & 11 & 6 & 11 & 6 & 11 & 6 & 10 & 6 & 11 & 6 \\
\hline Gestão Ambiental & 14 & 0 & 14 & 0 & 14 & 0 & 14 & 0 & 14 & 0 & 13 & 0 & 13 & 0 \\
\hline Impactos ao Meio Ambiente & 4 & 0 & 4 & 0 & 3 & 0 & 3 & 0 & 3 & 0 & 3 & 0 & 3 & 0 \\
\hline Mitigação de danos ao Meio Ambiente & 12 & 0 & 11 & 0 & 12 & 0 & 13 & 0 & 12 & 0 & 11 & 0 & 10 & 0 \\
\hline Energia & 5 & 0 & 5 & 0 & 5 & 0 & 7 & 0 & 7 & 0 & 5 & 0 & 6 & 0 \\
\hline Informações Financeiras Ambientais & 0 & 4 & 0 & 5 & 0 & 5 & 0 & 5 & 0 & 5 & 0 & 4 & 0 & 5 \\
\hline Educação e Pesquisa Ambiental & 6 & 0 & 6 & 0 & 6 & 0 & 8 & 0 & 7 & 0 & 7 & 0 & 7 & 0 \\
\hline Mercado de Créditos de Carbono & 4 & 0 & 4 & 0 & 4 & 0 & 5 & 0 & 5 & 0 & 3 & 0 & 3 & 0 \\
\hline Outras Informações Ambientais & 5 & 0 & 6 & 0 & 6 & 0 & 8 & 7 & 0 & 7 & 0 & 7 & 0 & 7 \\
\hline $\begin{array}{l}\text { Legenda da Evidência: } \\
\text { D - Declarativa } \\
\text { Q - Quantitativa }\end{array}$ & & & & & & & & & & & & & & \\
\hline
\end{tabular}

Fonte: Dados da Pesquisa, 2017

Verifica-se, na classificação da evidência, que mais de $60 \%$ das empresas divulgam as informações de maneira declarativa, ou seja, informações qualitativas expressas em termos descritivos, apenas. A subcategoria que obteve mais informações declarativas publicadas foi a de 'Gestão Ambiental', tendo 14 empresas relacionadas. Esse resultado é similar ao de Cunha, Beuren e Cardozo (2010). Destaca-se, ainda, que 100\% das empresas estudadas evidenciam a categoria de 'Informações Financeiras' quantitativamente, divulgando, principalmente, informações boas sobre os Investimentos praticados em prol do meio ambiente.

Pires e Silveira (2008) argumentam que além do aumento de informações, são sinais da evolução do processo de divulgação de informações de uma empresa, a apresentação das informações de caráter quantitativo, sejam elas monetárias e não monetárias, que complementam as declarativas. Os autores expõem: ainda que, devido ao fato de não existirem padrões que estabeleçam quais informações devem ser divulgadas, existe possibilidade de que elas sejam apresentadas de maneira superficial, ou seja, sejam meramente declarativas ou só reflitam a realidade que a empresa deseja divulgar.

\section{CONSIDERAÇÕES FINAIS}

A presente pesquisa objetivou analisar as características da informação ambiental divulgadas pelas empresas da construção civil listadas na B3. A avaliação das informações realizou-se através da análise de conteúdo das Demonstrações Financeiras Padronizadas (DFPs), dos Formulários de Referência, dos Relatórios Anuais (RAN) e de Sustentabilidade (RS), de 2010 a 2016. A amostra do estudo é composta por 18 empresas de capital aberto com ações negociadas na B3, e pertencentes ao segmento da construção civil.

A partir dos resultados encontrados, no período analisado, constatou-se que a companhia que obteve maior índice de itens divulgados foi a empresa Even, com cerca de 81,57\%. Observou-se que as empresas concentraram as informações ambientais, principalmente, nos 
Formulários de Referência, atingindo $83 \%$ da amostra. A participação é justificável pela exigibilidade da divulgação das atividades do emissor no referido formulário. De maneira geral, no que se refere ao tipo de notícia, foi possível perceber que cerca de $50 \%$ das empresas optam por divulgar notícias boas. Uma justificativa para isso, afirmada pela Teoria da Legitimidade, seria a tentativa de legitimar suas atividades empresariais, adotando posturas corretas perante a sociedade. As informações ruins compreenderam 6, das 18 empresas do estudo. Verificou-se que a maioria das informações foi divulgada pelas companhias de forma declarativa.

Esse estudo mostrou que, como enunciam as Teorias da Legitimidade e dos Stakeholders, as empresas, como forma de mostrar as suas ações, de modo a atender a demanda informacional das suas partes interessadas, e garantir a sua legitimidade, evidenciam informações de caráter ambiental, mesmo que não sejam obrigadas por força de lei, especialmente no Formulário de Referência, que passou a ser publicado pelas empresas a partir de 2010. Além disso, verifica-se a necessidade das empresas evidenciarem tais informações de maneira mais aprofundada, divulgando não apenas informações declarativas, ou seja, qualitativas, mas também quantitativas, assim como informações negativas, a fim de que os stakeholders tenham uma visão mais abrangente e verdadeira acerca da situação da empresa.

A pesquisa contribuiu para a compreensão dos conceitos e características da informação ambiental em geral, e, também, para a conscientização e preservação do meio ambiente. Dessa forma, os resultados desta pesquisa contemplam a Teoria da Legitimidade e a Teoria dos Stakeholders, tendo em vista que as empresas precisam ser aceitas pelas suas partes interessadas, assim como pela sociedade, e, por esse motivo, utilizam a divulgação ambiental como uma ferramenta de comunicação entre elas.

Ressalta-se que a análise de conteúdo expressa uma subjetividade expressiva em relação à interpretação dos itens, pertencentes a cada categoria. Caso outras pesquisas sejam replicadas, os resultados podem variar de acordo com o entendimento do pesquisador, sendo isso considerado, portanto, limitação da pesquisa. Propõe-se, para estudos futuros, uma análise com diferentes segmentos e a inclusão de novas variáveis para a análise da evidenciação ambiental.

\section{REFERÊNCIAS}

CARNEIRO, J.; LUCA, M.; OLIVEIRA, M. Análise das Informações Ambientais Evidenciadas nas Demonstrações Financeiras das Empresas Petroquímicas Brasileiras listadas na Bovespa.

Revista Contabilidade Vista e Revista, v. 19, n. 3, p. 39-67, 2008.

COSTA, R. D.; MARION, J. C. A Uniformidade na Evidenciação das Informações Ambientais. Revista Contabilidade \& Finanças, n. 43, p. 20-33, 2007.

CUNHA, P. R.; BEUREN, I. M.; CARDOZO, L. Evidenciação Social e Ambiental nos Relatórios da Administração de Empresas do Setor de Construção Civil. Revista Produção Online, v. 10, n. 2, p. 368-397, 2010.

CZESNAT, A. O.; MACHADO, D. D. P. N. Legitimação na evidenciação de informações socioambientais entre as empresas de telecomunicações listadas na Bovespa. Base - Revista de Administração e Contabilidade da Unisinos, v. 9, n. 3, p. 291-305, 2012. 


\section{REAVI}

DEEGAN, C. Introduction: The legitimising effect of social and environmental disclosures - a theoretical foundation. Accounting, Auditing \& Accountability Journal, v. 15, n. 3, p. 282 $311,2002$.

DYE, R. A. Disclosure of non-proprietary information. Journal of Accounting Research, v. 23, n. 1, p. 123-145, abr. 1985.

DYE, R. A. An evaluation of 'essays on disclosure' and the disclosure literature in accounting. Journal of Accounting and Economics, v.32, n.1, p. 181-235, 2001

EUGÊNIO, T. Avanços na Divulgação de Informação Social e Ambiental pelas Empresas e a Teoria da Legitimidade. Revista Universo Contábil, v. 6, n. 1, p. 102-118, 2010.

FARIAS, K. T. R. A relação entre divulgação ambiental, desempenho ambiental e desempenho econômico nas empresas brasileiras de capital aberto: uma pesquisa utilizando equações simultâneas. 2008. Dissertação (Mestrado em Controladoria e Contabilidade) Universidade de São Paulo, 2008.

FERNANDES, S. M. Fatores que Influenciam o Disclosure Ambiental: Um Estudo nas Empresas Brasileiras no Período de 2006 a 2010. Revista Ambiente Contábil, v. 5, n. 2, p. 250267, 2013

LADEIRA, D. Teoria dos Stakeholders no Contexto da Governança Corporativa: Um Estudo de Caso. 2009. Dissertação (Mestrado em Administração) - Faculdade de Ciências Empresariais, 2009.

LIMA, K. P. S. CUNHA, D. R.; MOREIRA, F. G. L.; PORTE, M. S. Contabilidade Ambiental: Um Estudo Sobre a Evidenciação das Informações Ambientais nas Demonstrações Contábeis das Grandes Empresas Brasileiras. Revista Eletrônica de Administração (Online), v. 11, n. 1, p. 1$14,2012$.

LU, Y.; ABEYSEKERA, I. Stakeholders' Power, Corporate Characteristics, and Social and Environmental Disclosure: Evidence from China. Journal of Cleaner Production, v. 64, p. 426436, 2014.

MAIA, P. As Fontes de Informação Ambiental: Uma Análise Sobre A Sua Aplicabilidade Pelos Profissionais da Secretaria de Estado de Meio Ambiente no Pará (Sema/PA). Revista ACB:

Biblioteconomia em Santa Catarina, v.15, n. 2, p. 54-70, 2010.

MENDES, G. C.; MOREIRA, L. L.; RODRIGUES, A. A. D. O. N. Um estudo sobre a evidenciação da responsabilidade social corporativa na construção civil. Revista Fafibe On-line, ano 5, n. 5, p. 1-10, 2012.

MURCIA, F. D.; ROVER, S.; LIMA, I.; FÁVERO, L. P. L.; LIMA, G. A. S. F. 'Disclosure Verde' nas Demonstrações Contábeis: Características da Informação Ambiental e Possíveis 


\section{REAVI}

Explicações para a Divulgação Voluntária. Revista UnB Contábil, v. 11, n. 1-2, p. 260-278, 2008.

MURCIA, F.; SANTOS, A.; SALOTTI, B. M.; NASCIMENTO, A. Mapeamento da Pesquisa Sobre Disclosure Ambiental no Cenário Internacional: Uma Revisão dos Artigos Publicados em Periódicos de Língua Inglesa no Período de 1997 a 2007. ConTexto, v. 10, n. 17, p. 7-18, 2010.

NOSSA, V. Disclosure Ambiental: Uma Análise do Conteúdo dos Relatórios Ambientais de Empresas do Setor de Papel e Celulose em Nível Internacional. Tese (Doutorado em Controladoria e Contabilidade) - Universidade de São Paulo, 2002.

PATTEN, D. M. Intra -industry Environmental Disclosures in Response to the Alaskan Oil Spill: A Note on Legitimacy Theory. Accounting, Organization and Society, v. 15, n. 5, p. 471-75, 1992.

PEREIRA, F. E.; LUZ, J. R. M.; CARVALHO, J. R. M. Evidenciação das Informações Ambientais das Empresas do Setor de Energia Elétrica do Brasil. Revista Evidenciação Contábil \& Finanças, v. 3, n. 2, p. 60-72, 2015.

PIRES, C. B.; SILVEIRA, F. C. S. A Evolução da Evidenciação das Informações Ambientais de Empresas do Setor de Celulose e Papel: Uma Análise de Conteúdo das Notas Explicativas e Relatórios de Administração. Contexto, v. 8, n. 13, jan./jun. 2008.

PLETSCH, C. S.; BRIGHENTI, J.; SILVA, A.; ROSA, F. S. Perfil da Evidenciação Ambiental das Empresas Listadas no Índice de Sustentabilidade Empresarial. Revista Contabilidade Vista \& Revista, v. 25, n. 3, p. 57-77, 2014.

ROSA, F. S.; VOSS, B. L.; ENSSLIN, S. R.; FELIU, V. R. Evidenciação ambiental: estudo comparativo das contribuições teórico-metodológicas de Brasil e Espanha. Revista Universo Contábil. Blumenal, v.8, n. 1, p. 123-140, 2012.

ROVER, S. Disclosure Ambiental de Empresas Potencialmente Poluidoras: Características da Informação Ambiental e Explicações para a Divulgação Voluntária no Brasil. 2009. 98 f. Dissertação (Mestrado em Ciências Contábeis) - Universidade Federal de Santa Catarina, 2009.

ROVER, S.; BORBA, J. A.; MURCIA, F. D. Características do Disclosure Ambiental de Empresas Brasileiras Potencialmente Poluidoras: Análise das Demonstrações Financeiras e dos Relatórios de Sustentabilidade do Período de 2005 a 2007. Contextus - Revista

Contemporânea de Economia e Gestão, v. 7, n. 1, p. 23-36, 2009.

SANTOS, L. M. S. Fatores Explicativos da Evidenciação de Informações Ambientais das Empresas Potencialmente Poluidoras Listadas na BM\&FBOVESPA. Dissertação (Mestrado em Ciências Contábeis) - Universidade Federal da Paraíba, 2016. 


\section{REAVI}

SANTOS, L. M. S.; LOPES, W. G. L.; SILVA, W. V.; BACH, T. M.; VEIGA, C. P.

Explanatory Factors of the Environmental Disclosure of Potentially Polluting Companies:

Evidence From Brazil. SAGE Open, p. 1-14, 2019.

TEIXEIRA, L.; CARVALHO, F. A Construção Civil como Instrumento do Desenvolvimento da Economia Brasileira. Revista Paraense de Desenvolvimento, n. 109, p. 09-26, 2005.

ULLMANN, A. E. Data in Search of a Theory: A Critical Examination of the Relationships Among Social Performance, Social Disclosure and Economic Performance of US Firms.

Academy of Management Review, v. 10, n. 3, p. 540-557, 1985.

VECHI, N. R. G. GALLARDO, A.L. C.F.; TEIXEIRA, C. E. Aspectos ambientais do setor da construção civil: roteiro para a adoção de sistema de gestão ambiental pelas pequenas e médias empresas de prestação de serviços. Sistemas \& Gestão - Revista Eletrônica, v. 11, n. 1, p. 17 $30,2016$.

VILHENA, J. Diretrizes para a Sustentabilidade das Edificações. Gestão \& Tecnologia de Projetos, v. 2, n. 2, p. 59-78, 2005. 